\title{
CORRECTION
}

\section{Correction to: Mapping adult plant stem rust resistance in barley accessions Hietpas-5 and GAW-79}

\author{
Austin J. Case ${ }^{1} \cdot$ Sridhar Bhavani $^{2} \cdot$ Godwin Macharia $^{3} \cdot$ Zacharias Pretorius $^{4} \cdot$ Vicky Coetzee $^{5} \cdot$ Frederik Kloppers $^{5}$. \\ Priyanka Tyagi $^{6}$. Gina Brown-Guedira ${ }^{7}$. Brian J. Steffenson ${ }^{1}$
}

Published online: 1 September 2018

○) Springer-Verlag GmbH Germany, part of Springer Nature 2018

\section{Correction to: Theoretical and Applied Genetics https://doi.org/10.1007/s00122-018-3149-8}

Unfortunately, one co-author name was incorrectly published in the original publication. The complete correct name should read as follows.

Frederik Kloppers

The original article has been updated.

The original article can be found online at https://doi.org/10.1007/ s00122-018-3149-8.

Brian J. Steffenson

bsteffen@umn.edu

1 Department of Plant Pathology, University of Minnesota, St. Paul, MN, USA

2 Centro Internacional de Mejoramiento de Maíz y Trigo (CIMMYT), Nairobi, Kenya

3 Kenya Agriculture and Livestock Research Organization (KALRO), Njoro, Kenya

4 Department of Plant Sciences, University of the Free State, Bloemfontein, Republic of South Africa

5 Pannar Seed (Pyt) Ltd, Greytown, Republic of South Africa

6 Department of Crop and Soil Sciences, North Carolina State University, Raleigh, NC 27695, USA

7 USDA-ARS, Raleigh, NC 27695, USA 